\section{Bag to school}

Johannes Zwerver, ${ }^{1}$ Robert-Jan de Vos ${ }^{2}$

\section{GROWTH AND INJURIES?}

Childhood and adolescence are characterised by marked somatic growth, and significant musculoskeletal, physiological and pubertal development. Musculoskeletal conditions become increasingly prevalent when growing up, and are thought to predict pain and disability later in life. ${ }^{1}$ However, Swain et al (see page 1246) dispute that there is a meaningful association between biological maturation, growth and musculoskeletal conditions in adolescence. They advise clinicians to refrain from inferring a causal relationship between maturity, growth and musculoskeletal conditions in adolescents. This raises the question of the specific role of loading in the growing child.

\section{OFFLOAD SCHOOLBAGS TO PREVENT BACK PAIN?}

Heavy schoolbags have traditionally been linked to back pain in children and adolescents, leading to ongoing discussions among parents, school teachers and scientists. An intriguing question is how much academic load (books!) can be carried safely by children. Yamato et al (see page 1241) show that there is no convincing evidence for back pain as a result of carrying schoolbags. They suggest that we should not be too overprotective when it comes to prescribing physical load and activity to children (figure 1).

\section{PHYSICAL ACTIVITY FOR SMART AND HEALTHY KIDS!}

Physical activity is considered to be important for growth, development and general health of children and adolescents. School-based physical activity interventions can improve cardiorespiratory fitness (see page 1234). There is even increasing evidence on the positive associations among physical activity, fitness, cognition and academic

${ }^{1}$ Department of Sports Medicine, University of Groningen, University Medical Center Groningen, Groningen, The Netherlands

${ }^{2}$ Department of Orthopaedics and Sports Medicine, Erasmus University Medical Center, Rotterdam, The Netherlands

Correspondence to Dr Robert-Jan de Vos, Department of Orthopaedics and Sports Medicine, Erasmus University Medical Centre, Rotterdam, 3015 CE, The Netherlands; r.devos@erasmusmc.nl

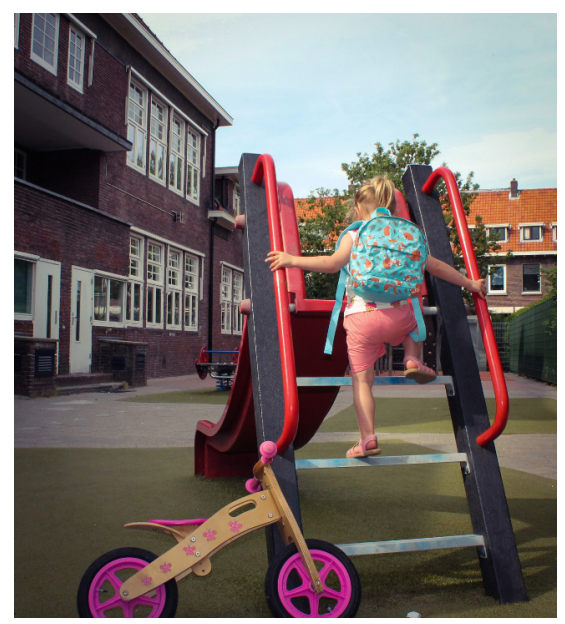

Figure 1 School bags are common on Dutch playing grounds.

achievement. ${ }^{2}$ However, the effects of numerous elements of physical activity on cognition remain to be explored, including type, amount, frequency and timing.

\section{REITERATING HEAVY LOADED BAGS FOR TENDON HEALTH}

The schoolbag and the questions about the type, amount, frequency and timing of loading, with or without pain, remind us of the classical paper on eccentric calf muscle strength training for mid-portion Achilles tendinopathy by Alfredson

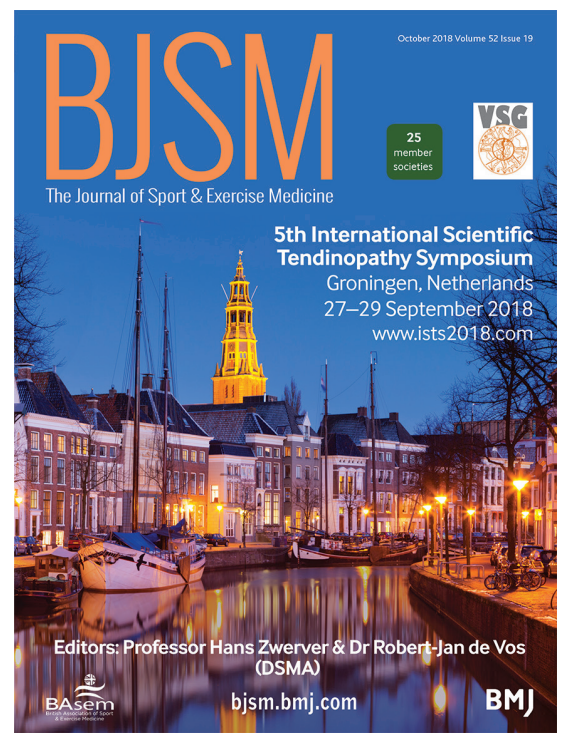

and coworkers. ${ }^{3}$ Twenty years later, this tendon-loading treatment still remains the cornerstone of treatment (figure 2).

The past two decades have seen a spectacular explosion of tendon research activities and fairly rapid changes in the management of tendinopathy. Despite this, tendon pain remains a challenging condition both for athletes and clinicians. We therefore organised the 5 th International Scientific Tendinopathy Symposium 2018 (https://www. ISTS2018.com) with a multidisciplinary team. Clinicians and researchers from all over the world came to Groningen, The Netherlands, to discuss 'healthy tendon ageing'. After three intensive days (and nights!?) they returned home with heavily loaded schoolbags full of new tendon knowledge and ideas.

\section{PERSONALISED LOAD MANAGEMENT TRUMPS THE 'ONE-SIZE-FITS-ALL' APPROACH}

The Dutch (https://www.sportgeneeskunde.com) edited issue of the British Journal of Sports Medicine (BJSM) contains many (see pages 1223, 1226, 1231 and 1267) sports medicine advances (see pages 1223, 1226, 1231 and 1267) on activity-dependent conditions. One theme is tendon conditions, from foot to shoulder (see pages 1224,

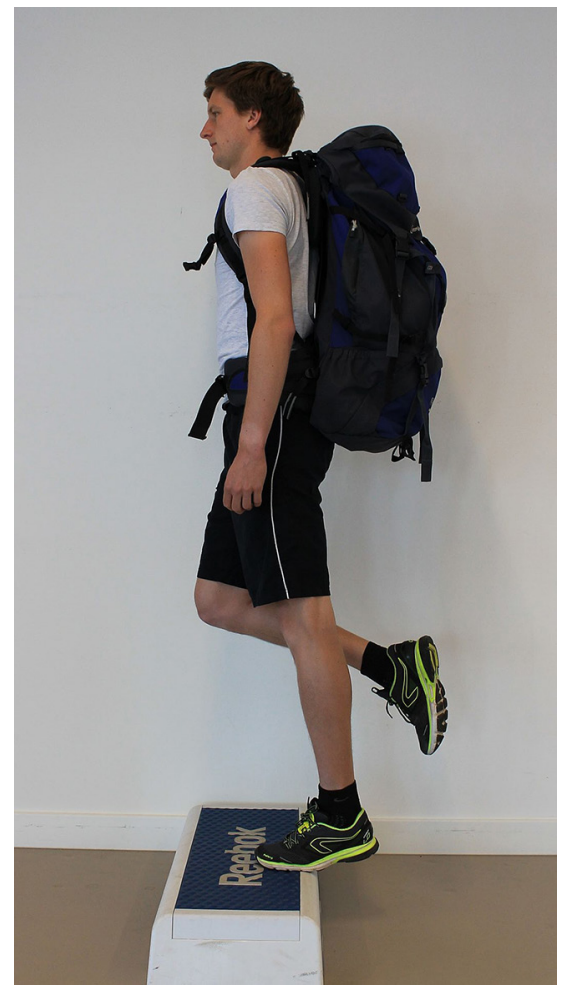

Figure 2 A Dutch version of Alfredson et al's $^{3}$ heavy-load eccentric calf muscle strength training using a backpack with weights. 
1221, 1232, 1261, 1275, e5 (online only) and 1222). Although it is tempting to look for 'one-size-fits-all' answers and treatments in tendinopathy and other conditions, we believe that loading should be personalised (see page 1232). You don't put the same number of books in the schoolbag of your 6-year-old daughter and 16-year-old son, do you?

\section{ACADEMIC LOADING: THE WAY TO IMPROVE SPORTS MEDICINE HEALTHCARE}

If you are not yet overloaded with knowledge, can we recommend the annual Dutch Scientific Sports Medicine and Sports Physiotherapy conference? It is a great opportunity to pick up even more sports medicine baggage for your backpack (29-30 November, Ermelo, The Netherlands; https://www.spor tmedischwetenschappelijkjaarcongres. nl). Although sports medicine is a young dynamic specialty, in the middle of its development and maturation, it is good to realise that the chance of getting back pain because of too much knowledge in the schoolbag is negligible. Because of their excellent 'core curriculum sports medicine training', Dutch sport medicine physicians can stand up straight with good posture and speak out loud that physical activity, including exercising and playing with personally loaded schoolbags, is good for the health, tendons and academic achievements. We look forward to seeing you at our conference and engaging with you on social media via the VSG Twitter account, \#HashtTagForErmelo, and BJSM's social media channels.

Contributors $\mathrm{JZ}$ and R-JdV wrote this warm up together on behalf of the Dutch Sports Medicine Association.

Competing interests None declared.
Patient consent Not required.

Provenance and peer review Commissioned; internally peer reviewed.

(C) Author(s) (or their employer(s)) 2018. No commercial re-use. See rights and permissions. Published by BMJ.

\section{Check for updates}

To cite Zwerver J, de Vos R-J. Br J Sports Med 2018;52:1219-1220.

Br J Sports Med 2018;52:1219-1220.

doi:10.1136/bjsports-2018-099929

\section{REFERENCES}

1 Pihlajamäki HK, Mattila VM, Parviainen M, et al. Longterm outcome after surgical treatment of unresolved Osgood-Schlatter disease in young men. J Bone Joint Surg Am 2009;91:2350-8.

2 Donnelly JE, Hillman CH, Castelli D, et al. Physical activity, fitness, cognitive function, and academic achievement in children: a systematic review. Med Sci Sports Exerc 2016;48:1197-222.

3 Alfredson $\mathrm{H}$, Pietilä T, Jonsson $\mathrm{P}$, et al. Heavy-load eccentric calf muscle training for the treatment of chronic Achilles tendinosis. Am J Sports Med 1998;26:360-6. 